\title{
Integration of a Nonpoint Source Pollution Model with a Decision Support System
}

\author{
L.F. León ${ }^{1}$, D.C. Lam ${ }^{2}$, D.A. Swayne ${ }^{3}$, G.J. Farquhar', E.D. Soulis ${ }^{1}$ \\ ${ }^{I}$ Civil Engineering, University of Waterloo, Waterloo, Ontario, Canada. (519) 885-1211 \\ Ifleonvi@uwaterloo.ca,fark@uwaterloo.ca,rsoulis@uwaterloo.ca \\ ${ }^{2}$ Environment Canada, National Water Research Institue, Burlington, Ontario, Canada. \\ (905)336-4916; david.lam@cciw.ca \\ ${ }^{3}$ Computer Science, University of Guelph, Guelph, Ontario, Canada. (519) 824-4120 \\ dswayne@snowhite.cis.uoguelph.ca
}

\begin{abstract}
This paper is a progress report of an ongoing research project from which the expected final product will be an integral system to model nonpoint source pollution in surface waters. Diffuse pollution models will be included in a decision support system with a unique platform, common interfaces and GIS capabilities. This system will accommodate pre- and postprocessing tools, model control and sensitivity analysis for the parameters in the models. Particularly, the construction of the interface for the AGNPS model and its link with the decision support system RAISON is presented. The model is described, including the input requirements, the development of tools and the procedures created to extract the necessary data from digital elevation model, soil type and landcover vectorized files.
\end{abstract}

\section{Keywords}

Spatial decision support system, nonpoint source pollution, model integration

\section{INTRODUCTION}

In the last two decades, nonpoint source pollution (NSP) has been a topic for research and the development of numerous models and modeling techniques. Most NSP models simulate hydrologic, chemical and physical processes involved in the entrainment and transport of sediment, nutrients and pesticides. The difficulty in modeling NSP is to identify the sources and quantify the loading. Contrary to a point source, where a known mass of contaminant is discharged from a single source, diffuse pollution is an aggregate of small contaminant inputs released from many sources spatially distributed through a watershed. Due to the complexity of the mechanisms involved in NSP, there is an increasing dependence on computerized runoff and transport models to assist in the planning and decision-making processes. 
Early models, developed at field scale, used the lumped-parameter approach, considering the area to be homogeneous and calculating a hydrologic response for the uniform area. As an extension to apply the lumped concept to larger areas, distributed-parameter models attempt to use the same mechanisms to all the fields in a watershed. In such models, the watershed is divided into individual and distinct elements in an effort to account for the spatial variability. Distributed models necessitate handling large amounts of data, thus increasing the effort required to collect it and compile the input files. On the other hand, the distributed approach lends itself well to a coupling with geographic information systems (GIS).

Data preparation for the models and results analysis are probably the most common problems encountered by model users. "Interactive programs are needed to assist model developers and users in processing data, initiating model simulations and analyzing model results using a variety of statistical and graphical techniques" (Leavesley et al., 1988). An integrated approach is being developed in this research. The idea involves linking the NSP models to a decision support system with GIS capabilities. This will provide easy data compiling for the models helping in the setup and simulation process. It will also assist with the interpretation of model results. Such a generic application could later be used to apply the models to various watersheds in order to validate hydrologic and water quality components.

\section{THE NSP MODEL}

Approaches to model agricultural diffuse pollution in surface waters vary widely. They include lumped- and distributed-parameter, continuous- and event-type models for use at field or watershed scales. The common elements among these models are the processes affecting the entrainment and transport of sediment, nutrients and pesticides in surface runoff. The dominant transport vector is runoff; while low intensity events produce little runoff, larger storms are generally responsible for the transport of pollution from wide areas. As a result, the majority of water quality models are attached to the ability to model surface runoff. Since the early 1970s, a large number of NSP models have been developed. Reviews of the available runoff-water quality models applicable to diffuse pollution modeling have been prepared by Giorgini and Zingales (1986), Donigian and Huber (1990). For this research the Agricultural Nonpoint Source Pollution Model (AGNPS) was selected.

The AGNPS model was developed by the United States Department of Agriculture at the Agriculture Research Service (Young et al., 1986), to obtain estimates of runoff quality with primary emphasis on nutrients, pesticides and sediments. Is a distributed model that simulates agricultural watersheds for a single storm event assuming uniform precipitation. Modeled watersheds by AGNPS must be divided into homogenous square working areas called cells. Subdivision of main cells into smaller sub-cells, gives flexibility to account for heterogeneity in the study area. Data needed for the model can be classified into two categories, watershed and cell data. The first include information applying to the entire watershed (e.g. size, number of cells, storm intensity, etc); the second include data of the parameters (approximately 22) based on soil type, landuse and management practices within the cell. Additional data are required if there is fertilizer or pesticide application, or if point sources are defined. If a cell contains data of all kind a total of 157 input parameters are required for that cell. 


\section{GIS AND DECISION SUPPORT SYSTEMS}

Geographical information systems can be thought as a means of storing and retrieving spatially varied data. In the strictest sense, GIS are computer systems capable of storing, manipulating and displaying geographically referenced information. They are ideally suited to study the processes and impact of diffuse pollution (Connors and Gardner, 1991). Information is stored for each grid element and several layers can be used to account for different types of data (i.e. elevation, soil type, and land use). Furthermore, in order to facilitate watershed management and planning, sources of information and knowledge are integrated into spatial decision support systems (SDSS). Lam et al. (1994) described an approach for an environmental information system using the Regional Analysis Information System (RAISON) as the base. It is expected that further development will allow it to become a powerful SDSS that will be part of the many research tools needed for better watershed management and planning. While there are some similarities to GIS, the RAISON system differs significantly as it emphasizes decision support and expert systems that are impossible to achieve with traditional GIS.

An important feature of RAISON used in this work, is its capability to incorporate modeling tools in the system. This is done by interfaces that interact with existing models and intercept the input and output to connect to the database in the system. As stated above, attempts to improve modeling capabilities need to be combined with the application of new technologies to resolve problems associated with ease of model use. This will allow the user to track the decision-making processes through the model to obtain a better understanding of the simulation. Three main aspects will be highlighted in the remain of the paper: flexibility, maximal use of GIS data and management engineering tool.

\section{AGNPS INTERFACE FOR RAISON}

An integral approach is used in this work involving the linkage of the AGNPS model and RAISON to form a SDSS to deal with NSP modeling. Interactive programs were created to assist in processing data, initiating model simulations and analyzing model results. Building up graphical interfaces allows interaction with the model by intercepting input/output and connecting them to the database in the system. Using topography, soil type and landuse maps in vector formats, procedures were developed to automate as much input data as possible. Design of a control panel for model operation helps in the setup and operation of the simulation. This also triggers the model to run and controls the mode of operation. Output analysis by means of graphical and statistical tools will assist with the interpretation of results.

\subsection{Description of the Toolbars and Procedures}

The design of the interface consists of a main window that controls the access to the different available toolbars (see Table 1). Each toolbar groups the different tasks or procedures to be performed in order to create/edit the grid, collect/edit the required data, run the model, display the results and perform the sensitivity analysis. Through the main interface the Create Grid and Edit Grid tools can be accessed to help with the elaboration of the grid and its edition by adding, deleting and subdividing cells. 
Table 1. Conceptual design of the Interface.

\begin{tabular}{lll}
\hline Toolbar & Tool/Procedure & Description \\
\hline Make/Edit Grid & Initialize Database & Initialize the database file and create the basic file structure. \\
& Create Grid & Create a basic grid and save to an existing database file. \\
& Create Tables & Create the required tables and structure for the AGNPS model. \\
& Edit Grid & Edit the grid by adding, deleting, and/or subdividing cells. \\
\hline Collect/Edit Data & Initial Data & Capture the initial watershed data. \\
& Collect Data & Extract data as function of topography, soil type, and landuse. \\
& Edit Flow Direction & Edit the flow directions and receiving cells. \\
& Cell Editor & View and edit the general cell data (access the additional data). \\
\hline Run AGNPS & Write ASCII File & Utility to convert the database to an ASCII file for the model. \\
& Run AGNPS Model & Run the AGNPS model for the selected file(s). \\
& AGNPS DOS Shell & Activates the AGNPS DOS Shell in a separate window. \\
\hline Display & Create/Edit Ranges & Create and edit ranges for the selected variable. \\
Input/Output & Display Input Data & Using the layer view, display the available input data. \\
& Display Output Data & Using the layer view, display the available output results. \\
\hline Sensitivity Analysis & Select Parameters & Choose parameters and range to perturb. \\
& Perform Sensitivity & Create files and run model in batch mode. \\
& Display Results & Display graphical results from the sensitivity runs. \\
\hline
\end{tabular}

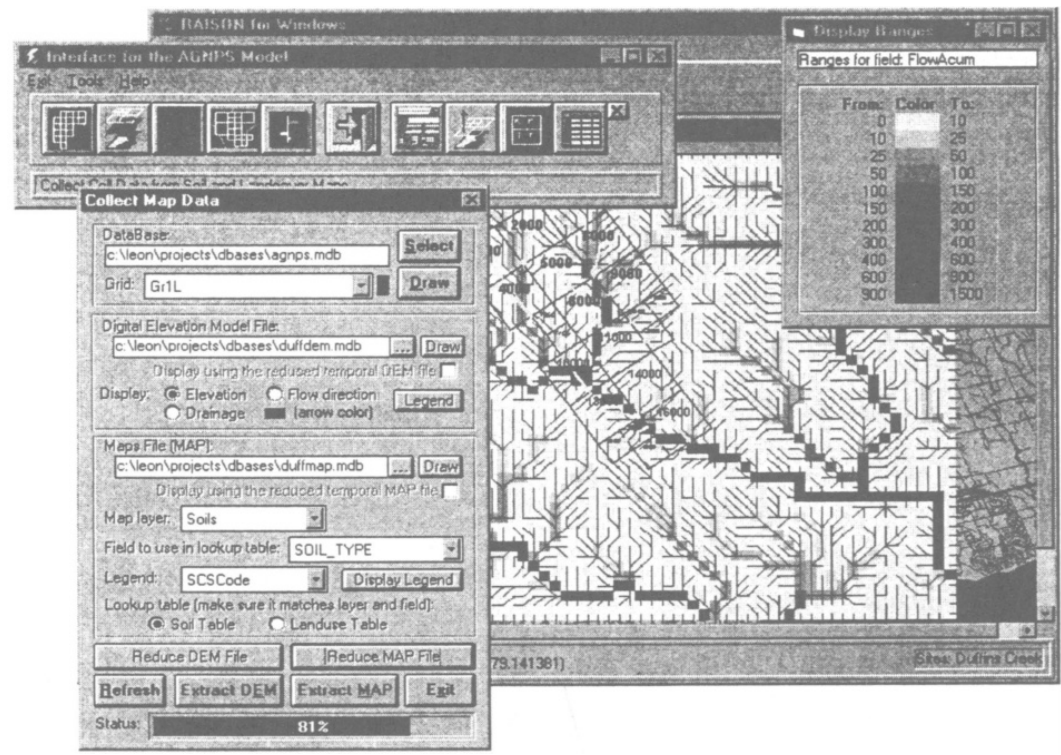

Figure 1. Display of the DEM file for the flow accumulation and flow direction fields.

After the grid is generated and the required tables (10 different tables) and database structure for the AGNPS model created to hold the data for the model, the next step is to start capturing the required data. The initial watershed data are captured directly into an input form that will verify if the data are valid and save them to the database. The major asset of the GIS approach is to automatically extract the required information for the model. Depending on the 
topography of the watershed and the configuration of the grid, some variables (e.g. receiving cell, flow direction, slope, etc.) are topographic related. Others are functions of the soil type and landcover (e.g. K factor, Manning's n, SCS curve number, etc.). To estimate these values, the Collect Data procedure was created. Figure 1 shows the Digital Elevation Model (DEM) with the drainage characteristic (flow accumulation) displayed, together with the grid and the calculated flow direction. The extraction process is activated with the extract command to perform the calculations for the variables that are dependent upon topography, soil or landuse for the selected grid and the active lookup table. It will browse the layer file looking for the intersection with every cell in the grid, calculating the area for each attribute (ie. soil type) and its percentage with respect to the total area of the cell. With this percentage it retrieves the values for the selected field in the lookup table and calculates the weighted value for the cell.

As an example of the way how polygon information is converted into model grid input data, Table 2 presents the detailed process for a variable dependent on the soil type field. It shows the calculations for an arbitrary cell to estimate the $\mathrm{K}$ factor for the Universal Soil Loss Equation (USLE). The map code is the original variable in the soil layer map file. Using this code and browsing through the lookup table, the soil texture and the $\mathrm{K}$ factor are retrieved from the database. Weighting the values according to the percentage of each soil type within the cell and adding them, give the value for the cell as accurately as it can be done.

Table 2. Sample calculation for a cell $\mathrm{K}$ factor value

\begin{tabular}{lllllll}
$\begin{array}{l}\text { Cell } \\
\text { Number }\end{array}$ & $\begin{array}{l}\text { Soil Type } \\
\text { Percent }\end{array}$ & $\begin{array}{l}\text { Map } \\
\text { Code }\end{array}$ & $\begin{array}{l}\text { Soil Texture in Lookup } \\
\text { Table (LUT) }\end{array}$ & $\begin{array}{l}\text { K factor } \\
\text { in LUT }\end{array}$ & $\begin{array}{l}\text { Weighted } \\
\text { K factor }\end{array}$ & $\begin{array}{l}\text { Accumulated } \\
\text { K factor }\end{array}$ \\
\hline 1000 & 0.1411 & B.L. & Bottom land:water-alluvial & 0 & 0.000 & 0.000 \\
1000 & 0.0274 & Pec & Peel : clay loam & 0.29 & 0.008 & 0.008 \\
1000 & 0.1074 & Ml & Milliken : loam & 0.31 & 0.033 & 0.041 \\
1000 & 0.0294 & Wol & Woburn : loam & 0.31 & 0.009 & 0.050 \\
1000 & 0.2248 & Ml & Milliken : loam & 0.31 & 0.070 & 0.120 \\
1000 & 0.1816 & Kis & King : silt loam & 0.37 & 0.067 & 0.187 \\
1000 & 0.1287 & Ml & Milliken : loam & 0.31 & 0.040 & 0.227 \\
1000 & 0.0422 & Cac & Cashel : clay & 0.20 & 0.008 & 0.236 \\
1000 & 0.0664 & Kis & King : silt loam & 0.37 & 0.025 & 0.260 \\
1000 & 0.0243 & Wol & Woburn : loam & 0.31 & 0.008 & $\mathbf{0 . 2 6 8}$ \\
\hline
\end{tabular}

In the same toolbar, the Cell Editor tool can be accessed in order to review the extracted data and/or edit any value if necessary. Figure 2 shows this tool with the results from the map extraction of the data. It can be noted that, in the background map, the soil type layer and its legend are displayed together with the arrows for the estimated flow direction. As previously mentioned, the AGNPS model can accommodate specific cell data, for example if the cell is selected for fertilizer or pesticide application. Also there is the possibility to attach point sources (ie. feedlots and non-feedlots), impoundment data and additional erosion. All these additional. data are captured through the use of input forms accessed from the Cell Editor tool. When any of these variables is selected for capture or edition, the correspondent window will open, allowing the user to enter the necessary data. Besides all this tools, and in order to enhance the system as a management tool, some scenario change is possible (e.g. change corn crop to soya or expand an urban site) by extracting the modified map file or editing cell values. 


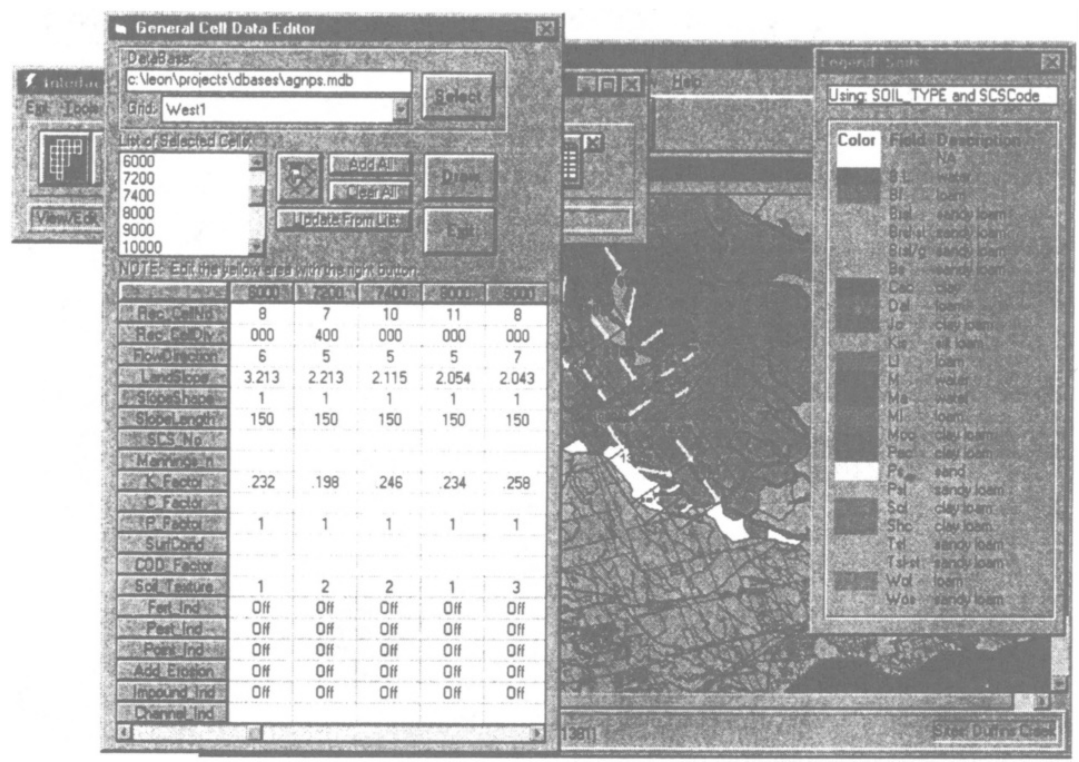

Figure 2. Cell editor showing the extracted values from DEM and soil type maps.

\subsection{Running the Model and Displaying Results}

Once the data has been captured and/or automatically collected from the maps with the described procedures and stored in the database file, the next step is to run the model and visualize the results. In order to run the AGNPS model, the data stored in the database has to be exported to an ASCII file in the format that the model can understand. This export and the actual running of the model can be done through the Run AGNPS toolbar. In this toolbar there are three procedures that write the ASCII file, run the model or activate a DOS shell that the AGNPS model provides to control the model. The recommended process to run the model from the interface is actually to select the Run AGNPS Model procedure. This creates a temporal ASCII file, runs the model and extracts the results from the output file, storing them in the unique database file in the system. Witte et al. (1995) found that for large watersheds the model should be run from outside the spreadsheet (DOS shell) program, so this is the approach used in this work to actually run any watershed size.

AGNPS output consists of a large amount of values for analysis, even for a small watershed. Graphical displays of the results have proven to be more effective for interpretation than browsing through pages of numerical output. Visual tools were created to display the spatial data in order to help with the analysis, interpretation and decision making processes. When the results are finally extracted from the output file and stored in the database, the Display Input/Output toolbar is selected to display the input data and/or the results from the simulation. As an example of the graphical tools available, Figure 3 presents the spatial display of the $\mathrm{K}$ factor (input data) and the sediment erosion (model result). 


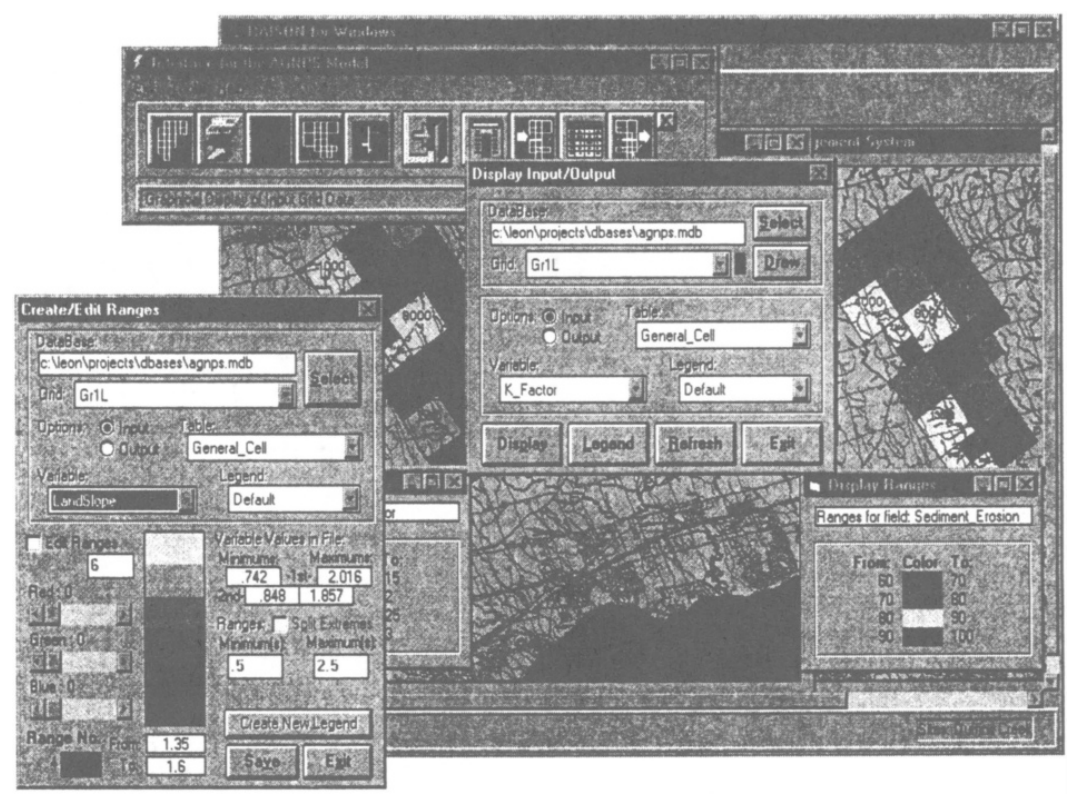

Figure 3. Example of spatial display for input/output data and model results.

\section{CONCLUSIONS}

It has been demonstrated how a NSP model was integrated with new technologies in order to improve data manipulation for input file creation, simulation control and interpretation of results. As mentioned, this paper is just a partial result of a research from which the principal objective is to create an integral system for NSP modeling in surface waters. This will be achieved through the linkage of distributed models within RAISON as the decision support system. Having an integral tool that will provide ease of use, analysis tools and graphic displays, all under a common framework is by itself a major improvement in NSP modeling.

\section{ACKNOWLEDGMENTS}

This work is part from the research proposal of Luis F. León for the fulfillment of the requirements for the Ph.D. in Civil Engineering at the University of Waterloo. CONACyT (Mexican Council for Science and Technology) has sponsored the scholarship of the author. The interactions with RAISON were developed by John D. McNeil and Jeff Berrardine whose participation is gratefully acknowledged. Thanks to Gary Bowen and others at the Ontario Ministry of the Environment and Energy for supplying data, support and advice. Special mention is due for the support of IMTA (Mexican Institute of Water Technology) and the NWRI (National Water Research Institute at Burlington, Canada). 


\section{REFERENCES}

Connors, K., Gardner, T.W. (1991) Watershed Configuration-Geographic Information System Parametrization: SPUR Model Hydrologic Simulation, Water Res. Bull., 27(1), pp 7-18.

Donigian, A.S., and Huber, W.C., (1990). Modeling Nonpoint Source Water Quality in Urban and Non-urban Areas, EPA 68-03-3513, Env. Research Lab., EPA, Athens, GA.

Giorgini, A., and Zingales, F., (1986). Agricultural Nonpoint Source Pollution: Model Selection and Application, Elsevier, Amsterdam.

Lam, D.C., Mayfield, C.I., Swayne, D.A. and Hopkins, K., (1994) A Protytype Information System for Watershed Management and Planning, Jr. Biol. Sys., Vol 2(4), pp. 499-517.

Leavesley, G.H., Beasley, D.B., Pionke, H.B., and Leonard, R.A., (1988) Modeling of Agricultural Nonpoint Source Surface Runoff and Sediment Yield - A Review from the Modeler's Perspective, Proc. Int. Symp. on Water Quality Modeling of Agricultural Nonpoint Sources, Part 1, Utah Univ., pp. 171-189.

Witte, J., Theurer, F.D., and Baker, K.D. (1995), AGNPS Version 5.0 Verification: Software, Technical Document File downloaded ftp.mrsars.usda.gov, USDA-ARS, Morris, MN.

Young R., Onstad, C., Bosch, D., Anderson, W., (1986). Agricultural Nonpoint Source Pollution Model: A Watershed Analysis Tool, Model Documentation, Agricultural Research Service, U.S. Department of Agriculture, Morris, MN.

\section{BIOGRAPHY}

Luis F. Leon - PEng, (Civil Engineering) BASc, 1982; MASc, 1990 (National Autonomous University of Mexico, UNAM). Currently is a full time $\mathrm{PhD}$ student at the University of Waterloo. The topic of research for his $\mathrm{PhD}$ involves the integration of a decision support system to model nonpoint source pollution in surface waters.

David C. Lam - The biography of Dr. Lam can be found elsewhere on this proceedings.

David A. Swayne -The biography of Dr. Swayne can be found elsewhere on this proceedings.

Grahame J. Farquhar - PEng, (Civil Engineering) BASc, 1964; MASc, 1968 (University of Waterloo) and PhD, 1968 (University of Wisconsin). Faculty member of the Civil Engineering Department at the University of Waterloo since 1968. He has taught courses, conducted research and provided professional services on environmental problems related to landfills, treating wastewaters and remediating contaminated soils.

Eric D. Soulis - PEng, (Civil Engineering) BASc (University of Waterloo), MEng (Memorial University), $\mathrm{PhD}$ (U. of Waterloo). Faculty member of the Civil Engineering Department at the University of Waterloo since 1988 . He combines teaching and research with his primary interest in remote sensing and the development of distributed hydrologic models. 